\title{
Islanding Detection in Rural Distribution Systems
}

\author{
Wen Fan ${ }^{1}$, Ning Kang ${ }^{2}$, Robert Hebner ${ }^{3, *}$ and Xianyong Feng ${ }^{3}$ \\ 1 Department of Electrical and Computer Engineering, University of Kentucky, Lexington, KY 40506, USA; \\ wen.fan@uky.edu \\ 2 Power and Energy Systems Department, Idaho National Laboratory, Idaho Falls, ID 83415, USA; \\ ning.kang@inl.gov \\ 3 Center for Electromechanics, University of Texas at Austin, Austin, TX 78758, USA; feng@cem.utexas.edu \\ * Correspondence: r.hebner@cem.utexas.edu
}

Received: 31 July 2020; Accepted: 16 October 2020; Published: 20 October 2020

check for updates

\begin{abstract}
This paper summarizes the literature on detection of islanding resulting from distributed generating capabilities in a power distribution system, with emphasis on the rural distribution systems. It is important to understand the legacy technology and equipment in the rural distribution electrical environment due to the growth of power electronics and the potential for adding the new generations of intelligent sensors. The survey identified four areas needing further research: 1 . Robustness in the presence of distribution grid disturbances; 2 . the future role of artificial intelligence in the islanding application; 3. more realistic standard tests for the emerging electrical environment; 4 . smarter sensors. In addition, this paper presents a synchro-phasor-based islanding detection approach based on a wireless sensor network developed by the University of Texas at Austin. Initial test results in a control hardware-in-the-loop (CHIL) simulation environment suggest the effectiveness of the developed method.
\end{abstract}

Keywords: distribution system; islanding; sensors; testing

\section{Introduction}

Like the preponderance of distribution systems, rural networks have historically been radial networks. A key difference is the distance between meters, and the likelihood that a large farm or ranch will have a larger electrical load than the load of a traditional residential consumer. The increasingly critical role played by electricity coupled with the large geographic vulnerability of the distribution system requires system operators to have better situational awareness and better control on their systems. Additionally, the decreasing cost of distributed energy resources (DERs) provides more incentive for the consumers to install DERs and provide electric power locally.

Earlier research has suggested that the operation state of equipment on a distribution feeder can be predicted based on the system model and data captured from the substation and smart meters [1]. While this approach is appealing, it is slow due to meter sampling intervals. The reduction in size, weight, and cost of processors and memory make it possible for the smart line-mounted sensors and advanced applications to improve the reliability, power quality, and system observability of general distribution network with large penetration DERs. This survey was conducted to support the development of such sensor systems, particularly those with the ability to identify unintentional islanding.

If a DER supplies electricity to a portion of the grid that is isolated from the utility grid, the isolated grid is islanded [2]. Islanding can cause adverse impacts on utilities and customers. Consequently, standards have been developed to specify the time by which an island situation must be cleared. For unintentional islanding, IEEE Std 1547-2018 requires that the DER should detect the island, cease to energize the area electric power system, and trip within 2 seconds of the formation of an island [3]. Thus, islanding detection methods are required for distribution system with DERs. 
While there are challenges in the system due to islanding, intentional islanding can be designed into the system for economic or resiliency reasons. A local grid, which can operate in grid-connected mode or island mode as well as incorporating the technology for a smooth mode transition, can be defined as a microgrid. The DER inverter system [4] in the microgrids usually works in current source control mode to provide power to the grid under normal operations. After being islanded, the inverter system must switch to the voltage control mode to provide voltage and/or frequency support to the local load. In addition to the mode transitioning from current source control to grid-forming control, the protection settings or other control settings such as frequency droop coefficient for DERs may also need to be adjusted right after the islanding happens. To effectively achieve the adaptive settings, accurate islanding detection function is required.

There are several adverse impacts associated with unintentional islanding [5]. First, unintentional islanding brings power quality issues to the customers. The abnormal voltage magnitude and power frequency due to the power mismatch may cause inconvenience to customers and may even damage their equipment. In addition, an islanded grid can also cause other adverse impacts while restoring the normal power delivery service to neighboring customers. Since DERs keep supplying power to the islanded grid, lines remaining energized can put utility crews and public safety in great danger if islanding is not detected. This will be more likely to happen in a distribution system with high penetration of DERs. Furthermore, DERs and other power equipment in the island could be damaged if the island is reconnected to the main grid without proper synchronization. Therefore, DERs are required to be disconnected during unintentional islanding [6] for human safety and distribution system reliability.

The motivation for this survey is to provide information that can support sensors used by system operators to identify unintentional islanding. The information is also technically relevant in microgrids and in more dense distribution systems.

This paper reviews the impacts of islanding and methods to detect islanding. The other contributions of this paper are listed below:

(1) The test approach for islanding detection algorithms is also summarized.

(2) This survey provides a summary of shortcomings and advantages of existing islanding detection methods.

(3) This survey suggests some potential research directions including robustness in the presence of distribution grid disturbances, the future role of artificial intelligence in the islanding application, more realistic standard tests for the emerging electrical environment, and smarter sensors.

(4) Based on the findings in the survey, the team has implemented a synchro-phasor based islanding detection approach based on a wireless sensor network developed by the University of Texas at Austin. This paper presents the new islanding detection approach and preliminary testing results in CHIL simulation environment.

\section{Existing Islanding Detection Methods}

Generally, islanding detection methods are classified as passive methods [7-14], active methods [15-28], and remote (communication-based) methods [29-31]. The classification is illustrated in Figure 1. The remote method uses power line signaling and transfers trip decision to DERs. [29]. 


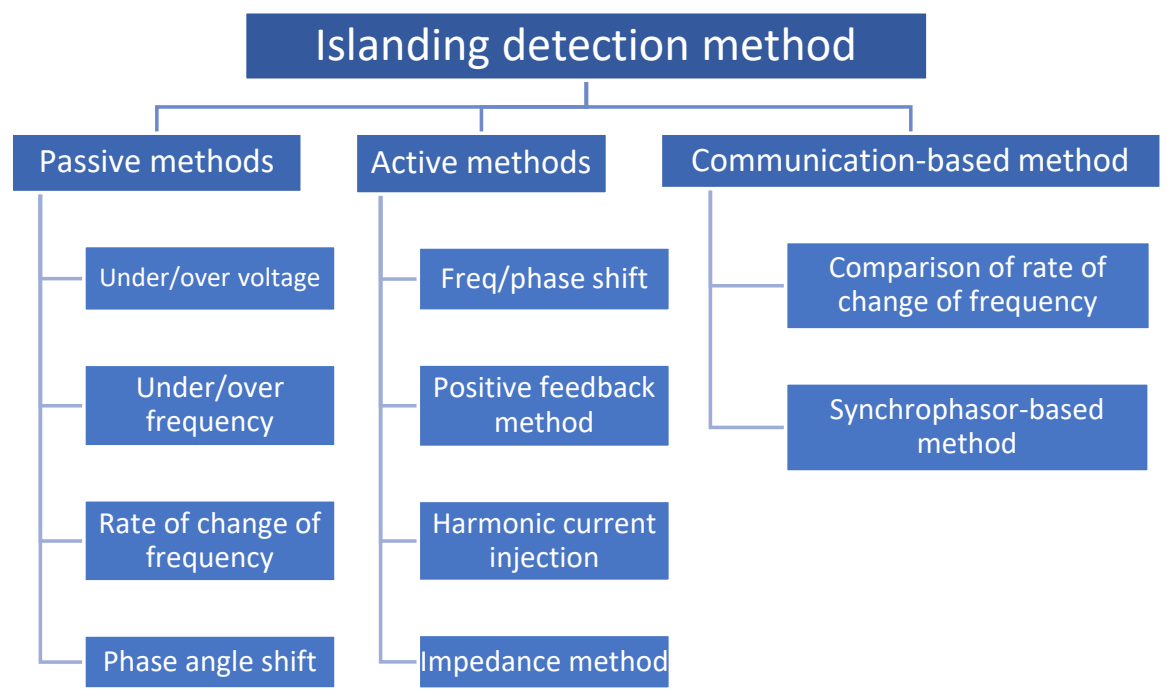

Figure 1. Islanding detection solutions classification.

\subsection{Passive Methods}

A conventional quality metric for islanding detection algorithms is the size of the non-detection zone (NDZ). Simply put, the NDZ is the portion of a distribution circuit in which islanding would not be detected if it occurred. In [7], an analytical approach was derived to visualize the NDZ for various passive islanding detection methods including under/over voltage, under/over frequency, and phase change. The test circuit, as shown in Figure 2, is the standard testing circuit in IEEE 1547.1-2005 [8], IEEE 929-2000 [6], and UL1741. The RLC load is used to perform theoretical analysis to estimate the NDZ of various methods.

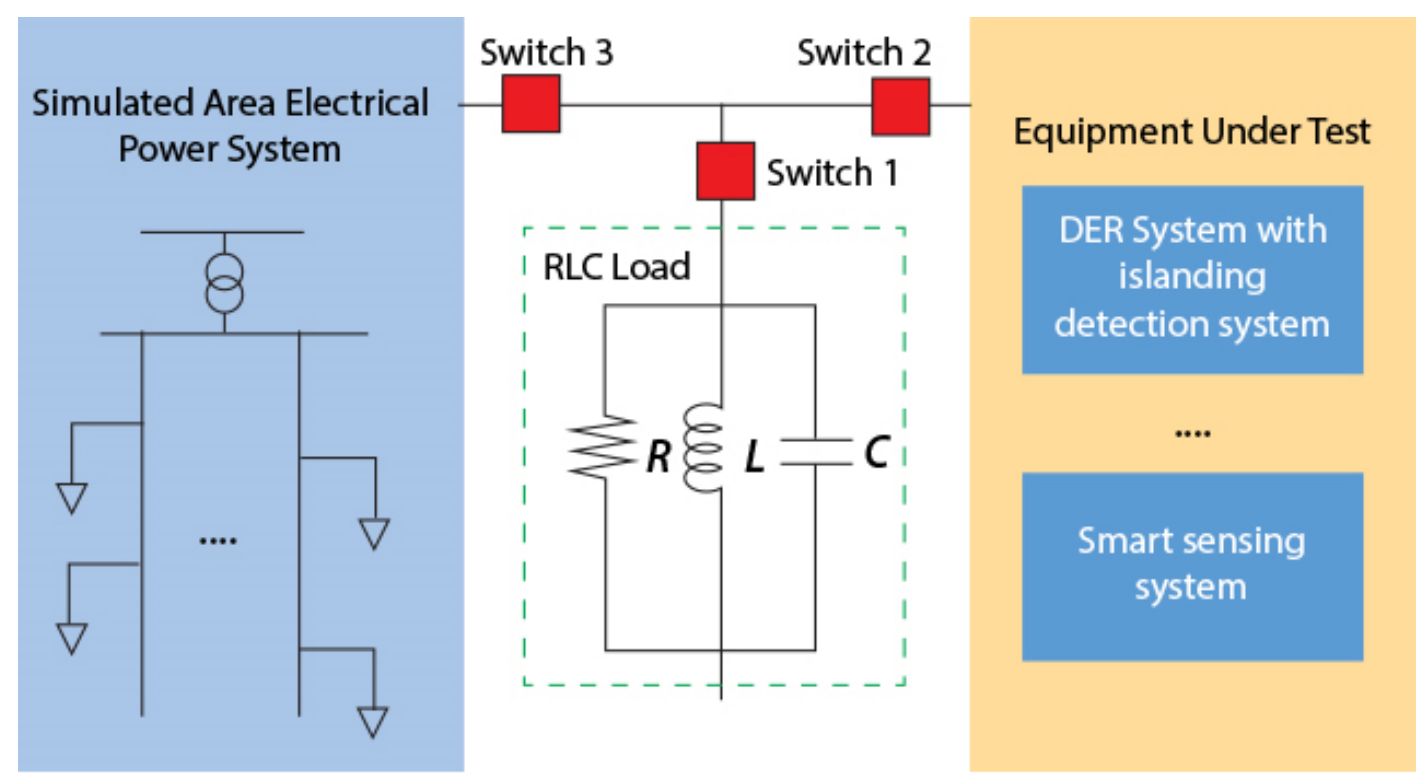

Figure 2. Unintentional islanding test configuration.

Passive methods use local voltage/frequency information to detect islanding. Any passive method [7,9] will fail the unintentional islanding test if the distribution generation (DG) power and load demand are $100 \%$ matched. This is because the islanding event would not cause obvious voltage and frequency variations, so the passive method would not be able to detect the event. Moreover, the island [7,9] can be undetectable with up to $30 \%$ power mismatch. In addition to the level issue, there is also a temporal behavior. When the power mismatch is larger than about $30 \%$, the frequency 
or voltage may take some time to deviate to the threshold and the time may be larger than the required value, i.e., 2 seconds as specified in IEEE 1547 [3]. Thus, the NDZ of the passive methods may be larger than the derived NDZ, as presented in [7].

Signal processing techniques are used to increase the utility of passive methods, for example, wavelet analysis technique. The wavelet transform and S-transform are used to extract features of the negative sequence voltage component [10]. The voltage signals are obtained from a hybrid system with photovoltaic (PV), wind, and fuel cell. In [11], the wavelet transform is used to extract detail coefficients at different levels of decomposition. Then, the detail coefficients are used to build a singular value matrix and calculate wavelet singular entropy for each phase. The simulation study shows this approach can detect islanding within 10 milliseconds.

Pattern recognition has also been used to detect islanding [12]. A random forest classification method is developed using features such as voltage, frequency, and total harmonic distortion. Evaluation studies based on the IEEE 34 bus system show that the provided method has zero NDZ. Lin et al. [14] report a wide-area measurement-based detection method for the bulk power system. It uses data captured by the frequency disturbance recorder and then examines frequency difference and change of angle difference. Simulation studies suggest that the method is immune to generation trips, load shedding, and system oscillations.

\subsection{Active Methods}

The active methods inject a disturbance into the system and use the responses to the disturbance to detect islanding. Lopes and Sun [15] assess the performance of an active frequency drifting islanding detection method. It uses a load parameter space that determined by the quality factor and resonant frequency of the RLC load. The authors claim that an NDZ is inevitable if considering all the quality factors. Karimi et al. [16] provide an islanding detection method that can prevent false trips for a single DER, which is connected to the main grid by a three-phase voltage sourced converter (VSC). A negative sequence current is injected through the VSC controller. Then, the corresponding negative sequence voltage at the point of common coupling (PCC) is measured. In reference [17], a dq frame technique is exploited as an active islanding detection method. Disturbance injected by the d-axis controller adjusts the voltage amplitude at PCC, while the q-axis controller injects a disturbance to alter the frequency at PCC. Simulation results show that injecting disturbance through the q-axis controller is a viable solution for islanding detection. Both simulations in $[16,17]$ are implemented in a PSCAD/EMTDC environment.

Kim et al. [18] detect islanding by injecting a ninth harmonic component into the current in the grid and analyzing the ninth harmonic component of the voltage at PCC. The Goertzel algorithm is used to reduce the computation burden. This approach uses the estimated grid impedance to detect unintentional islanding. The authors report that this method does not have any NDZ. Another injection alternative [19] is to detect islanding by injecting high-frequency voltage signals. The measurement of the grid high-frequency impedance is obtained and used to identify islanding in a few milliseconds.

An automatic phase shift method [20] detects islanding for grid-connected PV inverters. At the kth zero-crossing of the terminal voltage, while the frequency remains at normal line frequency, the output current at the inverter has its starting angle changed based on the frequency of previous voltage cycle. The developers assert that this method alleviated the non-detection problem. Chen and $\mathrm{Li}$ [21] analyze the connection of power mismatch and frequency deviation related to islanding. An indication of islanding is determined based on the large voltage deviation caused by active power mismatch.

Another impedance-measurement-based approach [22] is proposed for the PV inverter by injecting an inter-harmonic current and measuring the voltage response. The proposed approach was digitally implemented on the digital signal processor (DSP) of the PV inverter. The utility grid impedance was estimated using the existing sensors and DSP of the PV system. The accuracy of the method was tested in experimentally yielding less than $15 \%$ uncertainty for impedance estimation and less than $5 \%$ total harmonic distortion. 
An impedance variation approach using changes in active power and reactive power is proposed in $[23,24]$. The power quality perturbations were analyzed to capture the transient voltage and current signals to calculate the grid impedance. Unintentional islanding results in a detectable impedance change.

Reference [25] presents an attempt to improve islanding detection by using intermittent bilateral reactive power variation. The method adjusts the reactive power reference for the DER. Once unintentional islanding happens, the system frequency deviates from the nominal value and reaches the threshold in a short period of time. The approach is expected to eliminate the NDZ.

For most of these active methods, the NDZ could be effectively removed for single DER cases, but it may not be true for cases involving multiple-DER. Since the injected harmonics or the generated perturbations may be canceled due to multiple sources, the active method may not eliminate NDZ effectively for multiple-DER systems as suggested in [9].

A positive feedback approach for islanding detection $[9,26,27]$ was developed to address the challenge of multiple sources on the same distribution feeder. Positive feed control was achieved using a dq formulation. The control coefficients were also carefully selected based on an actual distributed generation system and grid properties to ensure that the applied positive feedback signal did not cause instability in grid-connected conditions. Experimental tests were used to verify the effectiveness of the proposed approach.

In general, active methods have smaller NDZ than passive approaches, but they perturb the system [28]. However, passive methods sometimes are not able to detect islanding when source and load are balanced [9].

\subsection{Communication-Based Methods}

The remote methods use communication between substation and DERs to detect the islanding. Such methods could eliminate NDZ and are suitable for a system with multiple DERs, but these methods require additional communication capability to enable a reliable islanding detection. One implementation [30] uses a phasor measurement unit (PMU) and intranet to implement the remote islanding detection method. The voltage angle difference between the utility grid and the DG site is calculated based on the local measured phase angle as well as the received grid phase angle. The angle difference threshold was selected as 120 degrees, which can achieve accurate islanding detection under conditions as small as $1 \%$ power mismatch. In this method, global positioning system (GPS), wide area network (WAN) communication over TCP/IP, and PMU are needed to accomplish the unintentional islanding detection.

Another approach [31] is to compare rate-of-change of frequency (COROCOF). The local measured rate-of-change of frequency (ROCOF) signal was compared with a reference signal from utility grid (i.e., a substation). If the local signal deviates from the reference signal and the difference exceeds a pre-specified threshold, an unintentional islanding event is detected. The threshold is based on the measurement accuracy and communication channel accuracy. Audio frequency signaling, radio signaling, or power line communication methods could be adopted to broadcast an event-triggered rate-of-change of frequency reference signal to the whole network. When a high ROCOF was detected locally, but the local device did not receive a reference signal, an unintentional islanding was detected.

\subsection{Hybrid Methods}

In addition, hybrid methods $[5,28,32-34]$ to detect islanding have been proposed. The hybrid methods combine active and passive methods. One such approach is to use voltage unbalance and total harmonic distortion of current [5]. The large or small variation in the loading of DER after islanding is considered.

An alternative method obtains phase criteria from the phase locked loop of the PV inverters [33]. The method predicts the ranges of loads that may possibly result in islanding undetected. Another approach is to combine the average rate of voltage change and real power shift to detect 
islanding with different load conditions for systems with multiple DERs [28]. The average rate of voltage change is used to initiate the real power shift.

Another hybrid method [32] combines total harmonic distortion with the principle of positive feeder technique. It discriminates between islanding and load switching. In [34], the approach of using wavelet analysis to obtain time localization of the islanding condition was assessed. In this approach, high-frequency components are injected by PV inverters, and then local measurements of controller voltage and current are obtained. In [35], a hybrid method is proposed to combine remote islanding detection signal from substation and local rate of change of voltage phase (ROCOVP) to improve the robustness of the islanding detection. The proposed method could eliminate NDZ and also be able to detect islanding in the presence of multiple DERs.

\subsection{Comparison of the Methods}

Various methods for islanding detection were reviewed in this Section. A comparison of the islanding detection methods is presented in Table 1.

Table 1. A comparison between the islanding detection methods.

\begin{tabular}{ccc}
\hline Methods & Pros & Cons \\
\hline Passive & $\begin{array}{c}\text { Incorporate the passive method with signal } \\
\text { process techniques and pattern recognition } \\
\text { enables fast islanding detection and } \\
\text { immunization to system parameter changes }\end{array}$ & $\begin{array}{c}\text { Cannot detect islanding if source and } \\
\text { load are balanced; cannot detect } \\
\text { islanding with 30+\% power mismatch. }\end{array}$ \\
\hline Active & $\begin{array}{c}\text { Usually have smaller NDZ than } \\
\text { passive methods }\end{array}$ & $\begin{array}{c}\text { Need to inject a disturbance, } \\
\text { which alter the system }\end{array}$ \\
\hline Communication-based & Can eliminate NDZ; suitable for a system \\
with multiple DERs & $\begin{array}{c}\text { Requires additional } \\
\text { communication capability }\end{array}$ \\
\hline Hybrid & Flexible to employ various methods together & $\begin{array}{c}\text { Complexity of the methods may add } \\
\text { burden to computation }\end{array}$ \\
\hline
\end{tabular}

\section{Islanding Detection Testing Approach}

Given the fact that various approaches have been proposed to measure all relevant electrical parameters to identify islanding, it is important to test these approaches to applicability in legacy systems. Test approaches range from offline simulation, to control hardware-in-the-loop (HIL) simulation, and to full-scale experiments. In most of the literature, off-line simulation was used. This is likely due to the combination of the fact that such simulation gives significant information and the tools for such simulations are widely available. Simulations are typically augmented by reduced scale experiments. IEEE 1547.1-2005 [8], IEEE 929-2000 [6], and UL1741 provide standard reduced scale test procedures.

Since an RLC load bank is used in the standard test circuit, the standard test scenario may not be able to emulate other load conditions, such as motor loads and power-electronic-interfaced loads. In addition, the test circuit may not be able to cover the systems with multiple DER units. Thus, the islanding detection performance in these cases may still need additional analysis to ensure that the developed islanding detection approaches could handle more complicated scenarios.

\section{Future Research Directions}

Even though various islanding detection methods have been developed in the past two decades and test techniques have been standardized, the changing electrical environment and technology advances have raised some research opportunities.

First, more efforts are needed to assure the island detection does not yield a false positive, needlessly interrupting service, due to disturbances in the grid. This is particularly important in a distribution grid, which can be electrically noisier than a transmission grid. If a grid disturbance occurs, the local DER should be able to ride-through the transient to maintain reliability. 
Second, the benefits of widespread edge computing for islanding detection need to be assessed. For example, the potential benefits of artificial intelligence tools need to be determined. An advertised but unpublished AI-based islanding detection approach has been explored by ABB [36]. It uses the estimated system inertia or system strength to detect unintentional islanding events, has been developed. This approach needs more extensive computation to run simulation studies to help better select adaptive settings for the algorithm. This approach would be more suitable for a future grid with more intermittent renewable resources and fast changing circuit topologies.

Third, research is needed to support more robust standard tests in the emerging electrical environment with much more power electronics integrated into the legacy grid.

Finally, the persistent development of more capable and smaller data excision and processing equipment as well as communications equipment, are making the development and deployment of distributed intelligent sensors throughout a distribution system possible. An intelligent sensor-based islanding detection method could be developed by leveraging the sensor's powerful computational capability and GPS synchronization capability as well as the communication network. The deployed low-cost intelligent sensors monitor the voltage and current on the line with GPS synchronization. Once a disturbance is recorded, the sensor can broadcast the information on the network. Each sensor will compare the broadcast signals with its local measurement to detect unintentional islanding. In addition, advanced system inertia estimation algorithm could be locally implemented on each intelligent sensor to estimate the real system strength in operational real time. Additional development and test work are still required in this area.

\section{Synchro-Phasor Based Islanding Detection Method}

The University of Texas at Austin team is developing a wireless sensor network for distribution system to monitor and detect abnormal conditions on the circuit [37]. Each line sensor has GPS synchronization and wireless communication capability. The line sensor is single-phase and is powered by the high voltage line directly. The sensor control function has been prototyped on National Instrument single-board RIO 9607 (NI sbRIO-9607) controller. The synchro-phasor measurement function is implemented on the FPGA of the NI sbRIO-9607 controller using Labview software. Standard P class and standard M class synchro-phasor measurement methods [38] are implemented on each sensor controller. P class method or $\mathrm{M}$ class method could be pre-configured based on requirement. In this work, P class was adopted to implement the islanding detection function. The synchro-phasor measurements include voltage, current, frequency, phase-angle, rate of change of frequency (ROCOF), and absolute timestamp.

In the sensor network, each intelligent sensor continuously monitors the local grid. Once a system disturbance (voltage, frequency, rate of change of frequency deviation above a threshold) is detected, the islanding detection function is activated. Each sensor will compare the local phasor measurement with its peers in terms of the phase angle difference. If the phase angle difference exceeds a pre-specified threshold and a high ROCOF is detected, an islanding event is detected. This method can further reduce the NDZ in islanding detection, as compared with local measurement-based approach.

The synchro-phasor data packet is buffered in direct memory access (DMA), first-in-first-out (FIFO) on FPGA. The microprocessor accesses the buffered data once certain number of data packets are available in the DMA FIFO. On the microprocessor, the standard TCP/UDP communication method is implemented to establish the data transmission between sensor controller and control center. The wireless LTE network is adopted in this sensor network to enable synchro-phasor data transmission. The measured round-trip time (RTT) of the wireless sensor network (LTE network) is less than $200 \mathrm{~ms}$. In the preliminary sensor testing, the synchro-phasor report rate is selected as 10 reports per second to achieve a trade-off between the wireless LTE network bandwidth and the islanding detection accuracy. 


\section{Preliminary Control Hardware-in-the-Loop Simulation Test Result}

To test the developed islanding detection methods, a relevant distribution system is constructed based on an operational distribution circuit from the project utility partner. The actual three-feeder circuit includes around 4000 single-phase nodes, 4600 elements, and 600 loads. It is relatively challenging to simulate the exactly-the-same system in real-time. To simulate the system in real-time and maintain the model fidelity, an aggregated system model for a single-feeder circuit model is developed. The simplified system includes 30 aggregated loads, 32 three-phase line segments, load switches, a capacitor bank, and one substation transformer. This model is implemented in the Matlab/Simulink simulation environment, as shown in Figure 3. The aggregated model accuracy is validated by the actual network model in OpenDSS software. The OpenDSS model is considered as an accurate representation of the feeder circuit. Various cases were compared including normal load flow and short-circuit fault current. In the worst case, the aggregated model has $1.5 \%$ error as compared with OpenDSS circuit model. The real-time model is implemented in Opal-RT simulator. The simulation time step is selected as $200 \mu \mathrm{s}$. It is validated that this model can run in real-time on the Opal-RT simulator.

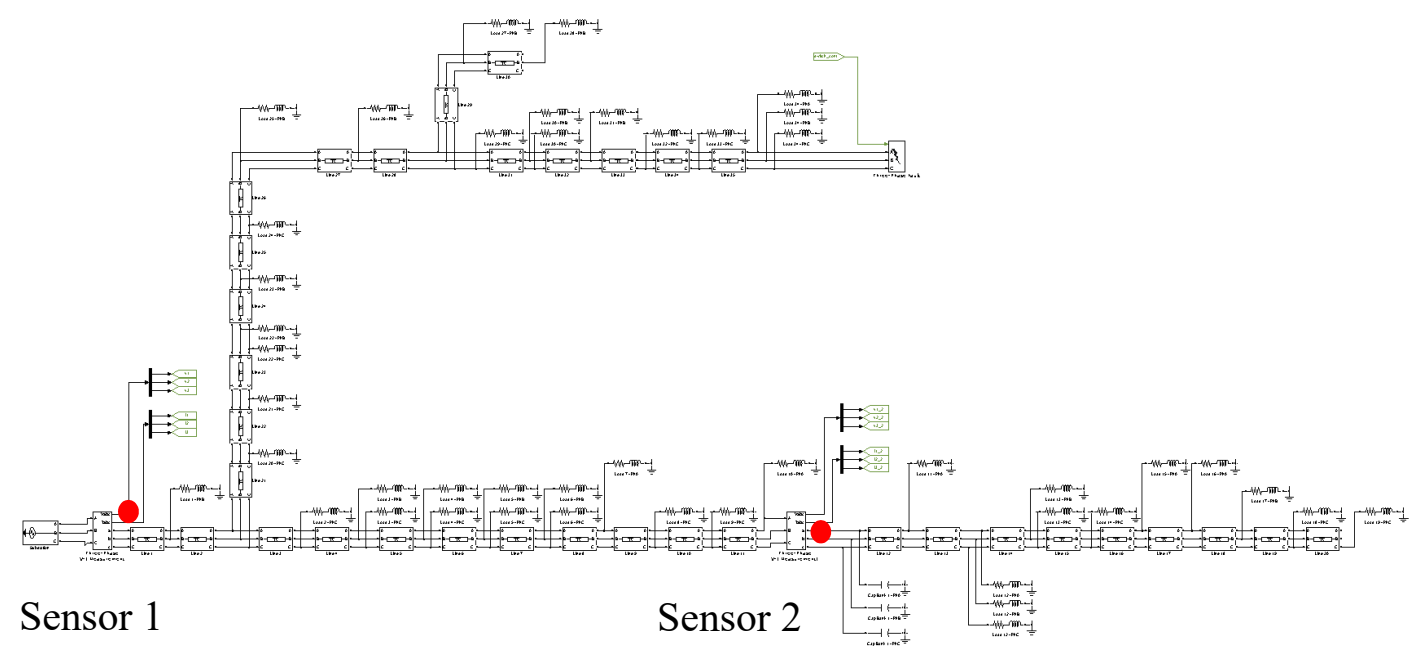

Figure 3. Diagram of the aggregated circuit model in Matlab/Simulink.

Two wireless sensors are integrated in the control-hardware-in-the-loop simulation environment. The GPS synchronization and wireless LTE communication functions are enabled on both sensor controllers. Both sensors are installed on phase A of the distributed feeder, as shown in Figure 3. Sensor 1 is installed at feeder head. Sensor 2 is installed right before capacitor bank. A switch is placed right before sensor 2. During the test, the initial status of the switch is close to emulate a grid-connected condition. In the simulation test, a signal is sent to the switch to open the line. The switch open creates an islanding event. The synchro-phasor report rate is configured as 10 reports per second. Each synchro-phasor report includes voltage phase angle, current phase angle, voltage magnitude, current magnitude, frequency, and rate of change of frequency. The synchro-phasor data from the sensor network are logged on a central computer for visualization and post analysis. When a sensor phase angle has a large mismatch with other sensors over 10 degree and a high ROCOF is detected, an islanding event is detected.

In the test, the system is initially operated in normal condition. Before the islanding happens, the voltage phase angles of sensor 1 and sensor 2 are very close, as shown in Figure 4a. The mismatch of phase angles is less than 2 degrees. In the distribution circuit, the physical distance of sensors is low. This guarantees that all sensors on the same phase have very close phase angle. Once islanding happens, the phase angle of the sensor in island area significantly deviates from the other sensors in grid-connected area. This provides a clear indicator for islanding event. The ROCOF also provides an 
indicator at the time instant of islanding event, as shown in Figure $4 \mathrm{~b}$. The current phase angle also starts oscillating during islanding condition, as shown in Figure $4 \mathrm{~d}$.

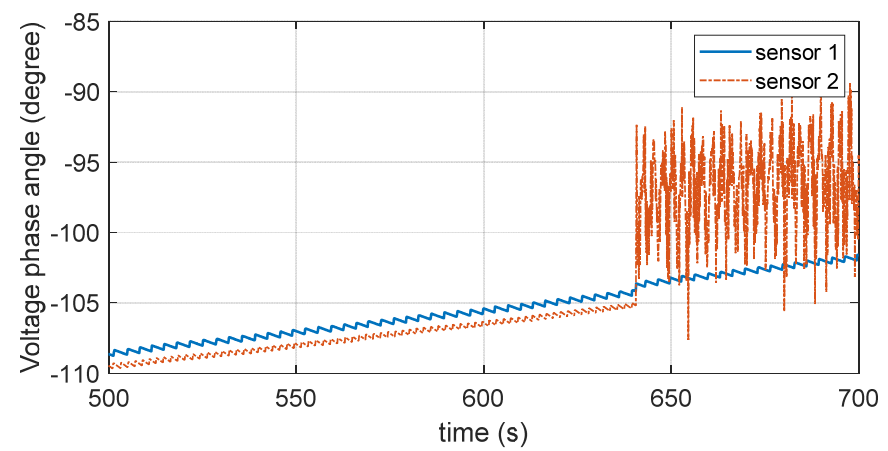

(a) Voltage phase angle.

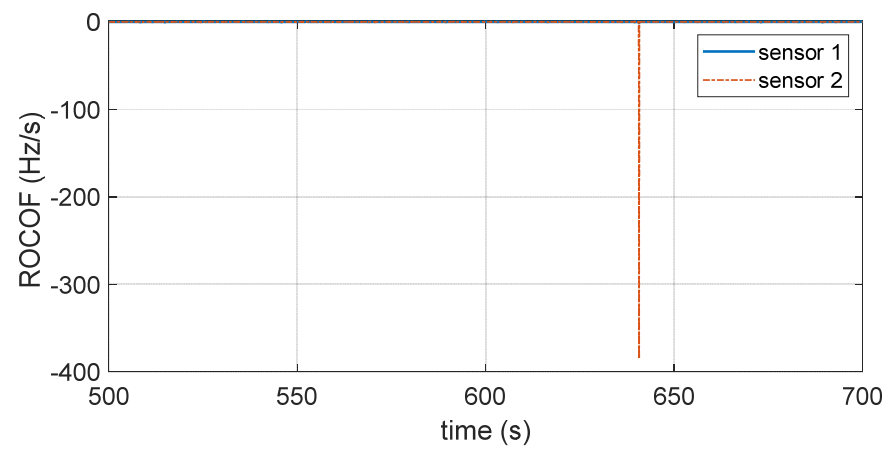

(b) Rate of change of frequency

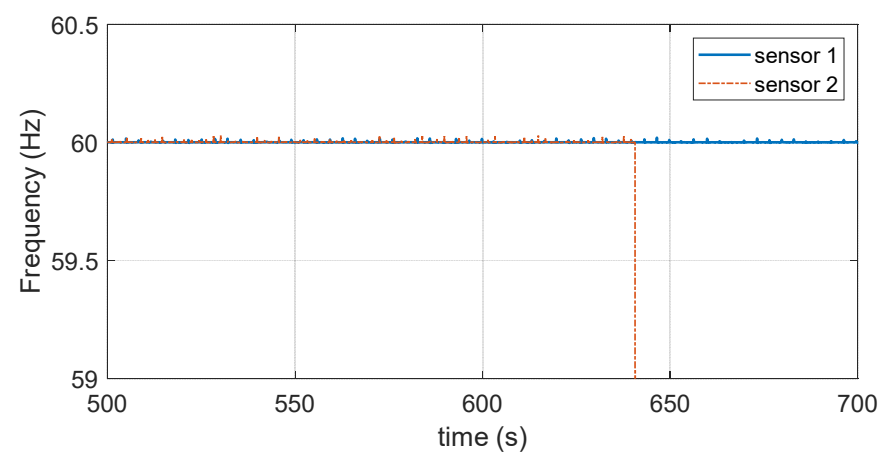

(c) Measured frequency

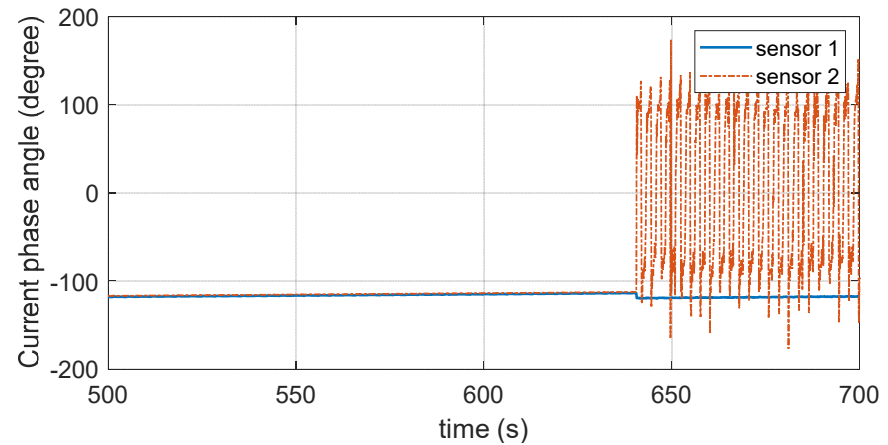

(d) Current phase angle

Figure 4. Islanding detection function test result. 
The preliminary test result suggests that the synchronized phase angle difference can provide a clear indicator for islanding event. This approach can be extended to a circuit with multiple sensors on the same phase. It should be noted that the preliminary test system is a rural distribution network, which does not have a significant amount of DERs. The proposed method has a great potential to be used to detect islanding in a system with extremely high DER penetration. Additional test results for high DER penetration grid will be presented in a future paper.

\section{Conclusions}

This paper first surveyed existing islanding detection methods in literature. The major focus of the survey is to understand the key challenges in islanding detection for high DER penetration grid and to identify the major practical solutions. Based on the survey, four potential research directions are identified including improving algorithm robustness, developing AI-based approach, improving test approach for emerging electrical environment, and smarter sensors. The smarter sensor technology is adopted by the team to improve the islanding detection performance.

Synchro-phasor based islanding detection is implemented on the wireless sensor network prototyped at the University of Texas at Austin. Standard P class synchro-phasor measurement method is used in the islanding detection. The GPS and wireless communication functions are implemented for the sensor controller to ensure that the synchro-phasor could be reliably transmitted to the central controller. Preliminary CHIL simulation testing is conducted in Opal-RT real-time digital simulator to validate the performance of the developed algorithm.

Future work will focus on improving the algorithm robustness and validating the performance in field. In addition, additional CHIL tests will be performed to show the performance of the developed synchro-phasor based islanding detection method in high DER penetration grid.

Author Contributions: Conceptualization, W.F., N.K., and X.F.; investigation, N.K.; writing一original draft preparation, W.F., N.K., X.F., and R.H.; writing-review and editing, R.H.; supervision R.H.; funding acquisition, R.H., X.F., and N.K. All authors have read and agreed to the published version of the manuscript.

Funding: This research was funded by the US Department of Energy, Agreement DE-OE0000873. This work was funded as portion of a research project partially funded by the US Department of Energy.

Conflicts of Interest: The authors declare no conflict of interest. The funders had no role in the design of this survey; in the collection, analyses, or interpretation of data; in the writing of the manuscript, or in the decision to publish the results. The portion of Ning Kang and Wen Fan's work was accomplished at Argonne National Lab.

\section{References}

1. Uriarte, F.; Toliyat, A.; Kwasinski, A.; Hebner, R. Consumer-data approach to assess the effect of residential grid-tied photovoltaic systems and electric vehicles on distribution transformers. In Proceedings of the IEEE 5th International Symposium on Power Electronics for Distributed Generation Systems, Galway, Ireland, 24-27 June 2014; pp. 1-8.

2. Walling, R.A.; Saint, R.; Dugan, R.C.; Burke, J.; Kojovic, L.A. Summary of distributed resources impact on power delivery systems. IEEE Trans. Power Deliv. 2008, 23, 1636-1644. [CrossRef]

3. IEEE Standard for Interconnection and Interoperability of Distributed Energy Resources with Associated Electric Power Systems Interfaces; IEEE Std 1547-2018 (Revision of IEEE Std 1547-2003); IEEE: Piscataway, NJ, USA, 2018; pp. 1-138.

4. Balaguer, I.J.; Lei, Q.; Yang, S.; Supatti, U.; Peng, F.Z. Control for grid-connected and intentional islanding operations of distributed power generation. IEEE Trans. Ind. Electron. 2011, 58, 147-157. [CrossRef]

5. Jang, S.-I.; Kim, K.-H. An islanding detection method for distributed generations using voltage unbalance and total harmonic distortion of current. IEEE Trans. Power Deliv. 2004, 19, 745-752. [CrossRef]

6. IEEE Standards Coordinating Committee 21. IEEE Recommended Practice for Utility Interface of Photovoltaic (PV) Systems; IEEE Std 929-2000; IEEE: Piscataway, NJ, USA, 2000.

7. Ye, Z.; Kolwalkar, A.; Zhang, Y.; Du, P.; Walling, R. Evaluation of anti-islanding schemes based on nondetection zone concept. IEEE Trans. Power Electron. 2004, 9, 1171-1176. [CrossRef] 
8. IEEE Standards Coordinating Committee 21. IEEE Standard for Conformance Test Procedures for Equipment Interconnecting Distributed Resources with Electric Power Systems; IEEE Std 1547.1 ${ }^{\mathrm{TM}}-2005$; IEEE: Piscataway, NJ, USA, 2005.

9. Ye, Z.; Walling, R.; Garces, L.; Zhou, R.; Li, L.; Wang, T. Study and Development of Anti-Islanding Control for Grid-Connected Inverters; Technical Report; Rep. NREL/SR-560-36243; National Renewable Energy Lab: Golden, CO, USA, 2004.

10. Ray, P.K.; Kishor, N.; Mohanty, S.R. Islanding and power quality disturbance detection in grid-connected hybrid power system using wavelet and S-transform. IEEE Trans. Smart Grid 2012, 3, 1082-1094. [CrossRef]

11. Samui, A.; Samantaray, S.R. Wavelet singular entropy-based islanding detection in distributed generation. IEEE Trans. Power Deliv. 2013, 28, 411418. [CrossRef]

12. Faqhruldin, O.N.; El-Saadany, E.F.; Zeineldin, H.H. A universal islanding detection technique for distributed generation using pattern recognition. IEEE Trans. Smart Grid 2014, 5, 1985-1992. [CrossRef]

13. Zeineldin, H.H.; Abdel-Galil, T.; El-Saadany, E.F.; Salama, M.M.A. Islanding detection of grid connected distributed generators using TLS-ESPRIT. Electr. Power Syst. Res. 2007, 77, 155-162.

14. Lin, Z.; Xia, T.; Ye, Y.; Zhang, Y.; Chen, L.; Liu, Y.; Tomsovic, K.; Bilke, T.; Wen, F. Application of wide area measurement systems to islanding detection of bulk power systems. IEEE Trans. Power Syst. 2013, 28, 2006-2015. [CrossRef]

15. Lopes, L.A.C.; Sun, H. Performance assessment of active frequency drifting islanding detection methods. IEEE Trans. Energy Convers. 2006, 21, 171-180. [CrossRef]

16. Karimi, H.; Yazdani, A.; Iravani, R. Negative-sequence current injection for fast islanding detection of a distributed resource unit. IEEE Trans. Power Electron. 2008, 23, 298-307. [CrossRef]

17. Hernandez-Gonzalez, G.; Iravani, R. Current injection for active islanding detection of electronically-interfaced distributed resources. IEEE Trans. Power Deliv. 2006, 21, 1698-1705. [CrossRef]

18. Kim, J.; Kim, J.; Ji, Y.; Jung, Y.; Won, C. An islanding detection method for a grid-connected system based on the goertzel algorithm. IEEE Trans. Power Electron. 2011, 26, 1049-1055. [CrossRef]

19. Reigosa, D.; Briz, F.; Charro, C.B.; Garcia, P.; Guerrero, J.M. Active islanding detection using high-frequency signal injection. IEEE Trans. Ind. Appl. 2012, 48, 1588-1597. [CrossRef]

20. Hung, G.-K.; Chang, C.-C.; Chen, C.-L. Automatic phase-shift method for islanding detection of grid-connected photovoltaic inverters. IEEE Trans. Energy Convers. 2003, 18, 169-173. [CrossRef]

21. Chen, X.; Li, Y. An islanding detection algorithm for inverter-based distributed generation based on reactive power control. IEEE Trans. Power Electron. 2014, 29, 4672-4683. [CrossRef]

22. Asiminoaei, L.; Teodorescu, R.; Blaabjerg, F.; Borup, U. A digital controlled PV inverter with grid impedance estimation for ENS detection. IEEE Trans. Power Electron. 2015, 20, 1480-1490. [CrossRef]

23. Timbus, A.V.; Teodorescu, R.; Rodriguez, P. Grid impedance identification based on active power variations and grid voltage control. In Proceedings of the IEEE Industry Applications Annual Meeting, New Orleans, LA, USA, 23-27 September 2007.

24. Ciobotaru, M.; Teodorescu, R.; Rodriguez, P.; Timbus, A.; Blaabjerg, F. Online grid impedance estimation for single-phase grid-connected systems using PQ variations. In Proceedings of the IEEE Power Electronics Specialists Conference, Orlando, FL, USA, 17-21 June 2007; pp. 2306-2312.

25. Zhang, J.; Shen, G.; Zhu, Y.; Ma, J. An improved islanding detection method for a gridconnected inverter with intermittent bilateral reactive power variation. IEEE Trans. Power Electron. 2013, 28, 268-278. [CrossRef]

26. Du, P.; Ye, Z.; Aponte, E.E.; Nelson, J.K.; Fan, L. Positive-feedback-based active anti-islanding schemes for inverter-based distributed generators: Basic principle, design guideline and performance analysis. IEEE Trans. Power Electron. 2010, 25, 2941-2948.

27. Ye, Z. A new family of active anti-islanding schemes based on DG implementation for grid-connected inverters. In Proceedings of the IEEE 35th Annual Power Electronics Specialists Conference, Aachen, Germany, 20-25 June 2004; pp. 235-241.

28. Mahat, P.; Chen, Z.; Bak-Jensen, B. A hybrid islanding detection technique using average rate of voltage change and real power shift. IEEE Trans. Power Deliv. 2009, 24, 764-771. [CrossRef]

29. Xu, W.; Zhang, G.; Li, C.; Wang, W.; Wang, G.; Kliber, J. A power line signaling based technique for anti-islanding protection of distributed generators-Part I: Scheme and analysis. IEEE Trans. Power Deliv. 2007, 22, 1758-1766. [CrossRef] 
30. Ishibashi, A.; Imai, M.; Omata, K.; Sato, S.; Takagi, T.; Nakachi, Y.; Ogawa, S. New type of islanding detection system for distributed generation based on voltage angle difference between utility network and distributed generation site. In Proceedings of the 2004 Eighth IEE International Conference on Developments in Power System Protection, Amsterdam, The Netherlands, 5-8 April 2004.

31. Bright, C.G. COROCOF: Comparison of rate of change of frequency protection. A solution to the detection of loss of mains. In Proceedings of the IEE Seventh International Conference on Developments in Power System Protection, Amsterdam, The Netherlands, 9-12 April 2001.

32. Menon, V.; Nehrir, M.H. A hybrid islanding detection technique using voltage unbalance and frequency set point. IEEE Trans. Power Syst. 2007, 22, 442-448. [CrossRef]

33. Ropp, M.E.; Begovic, M.; Rohatgi, A.; Kern, G.A.; Bonn, R.H.; Gonzalez, S. Determining the relative effectiveness of islanding detection methods using phase criteria and nondetection zones. IEEE Trans. Energy Convers. 2000, 15, 290-296. [CrossRef]

34. Pigazo, A.; Liserre, M.; Mastromauro, R.A.; Moreno, V.M.; Dell'Aquila, A. Wavelet based islanding detection in grid-connected PV systems. IEEE Trans. Ind. Electron. 2009, 56, 4445-4455. [CrossRef]

35. Pouryekta, A.; Ramachandaramurthy, V.K.; Mithulananthan, N.; Arulampalam, A. Islanding detection and enhancement of microgrid performance. IEEE Syst. J. 2018, 12, 3131-3141. [CrossRef]

36. Gill, S.; Vo, K. Speed Up the Adoption of DERs and Improve Safety with AI-Based Islanding Detection at Your Utilities and Industrial Facilities; ABB: Zürich, Switzerland, 2018.

37. Feng, X.; Hebner, R.E.; Strank, S. Design consideration for power line sensors in power distribution systems. In Proceedings of the IEEE Energy Conversion Congress and Exposition, Detroit, MI, USA, 11-15 October 2020.

38. IEEE Standard for Synchrophasor Measurements for Power Systems; IEEE Std C37.118.1-2011; IEEE Power \& Energy Society: Piscataway, NJ, USA, 2011.

Publisher's Note: MDPI stays neutral with regard to jurisdictional claims in published maps and institutional affiliations. 